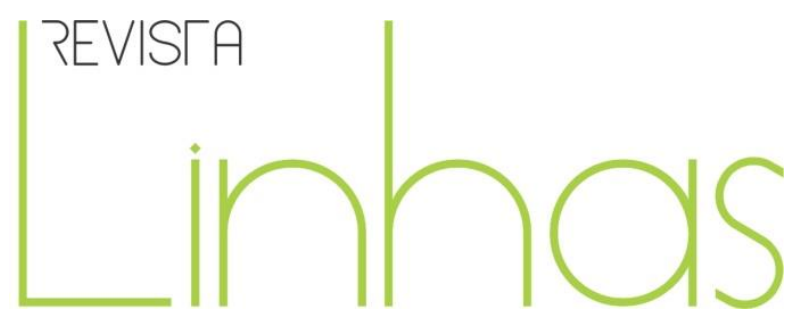

\title{
Ensinar a sociologia na França. Uma prática pedagógica entre reflexividade e restrições
}

\section{Resumo}

A questão pedagógica na universidade é identificada entre a indiferença, por um lado, e a institucionalização em serviços dedicados e dispositivos periféricos, por outro. Este artigo propõe uma terceira via, que consiste em internalizar a reflexão pedagógica no centro das aulas temáticas para torná-la uma dimensão essencial e legítima da profissão de professor(a)-pesquisador(a). Com base na auto-análise de suas práticas de ensino em duas universidades, Delphine Serre mostra como a sociologia pode ser um recurso para criar, ministrar e avaliar cursos. Ela explica primeiro os dois princípios pedagógicos, inspirados no trabalho sociológico, que norteiam suas práticas: a de uma "pedagogia envolvente" e de uma "pedagogia racional". Em seguida, mostra como mobiliza a prática reflexiva da sociologia e suas ferramentas (questionários, observações) para melhor adequar as lições ao público. Por fim, expõe os limites que se impõem a essa reflexividade pedagógica, devido às condições materiais e institucionais que caracterizam o trabalho de professores(as) e pesquisadores(as). Longe de promover uma enésima inovação pedagógica, o artigo pretende ser uma contribuição modesta, baseada em uma experiência pessoal, para colocar em evidência uma reflexividade educacional comum que foi prejudicada por reformas recentes no ensino superior.

Palavras-chave: Ensino de sociologia. Pedagogia racional. Desigualdades das condições de estudo. Pedagogia universitária. Avaliação de aulas pelos alunos. Condições de trabalho dos professores-pesquisadores.

\author{
Delphine Serre \\ Université Paris Descartes - \\ França \\ delphine.serre@parisdescartes.fr
}

\section{Para citar este artigo:}

SERRE, Delphine. Ensinar a sociologia na França. Uma prática pedagógica entre reflexividade e restrições. Revista Linhas. Florianópolis, v. 21, n. 45, p. 46-77, jan./abr. 2020. Título original: Enseigner la sociologie en France. Une pratique pédagogique entre réflexivité et contraintes. Tradução: Fernando Coelho. 


\title{
Teaching sociology in France. A pedagogical practice between reflexivity and constraints
}

\begin{abstract}
The pedagogical question in French higher education is caught in a vice between indifference and institutionalization in dedicated services. This article proposes a third way, which consists in internalizing pedagogical concern within thematic courses to make it an essential and legitimate dimension of the teaching at the university. Based on a self-analysis of her teaching practices in two universities, Delphine Serre shows how sociology can be a resource for making, delivering and evaluating courses. First, she explains her two teaching guidelines, "enveloping pedagogy" and "rational pedagogy" (inspired from Pierre Bourdieu and Jean-Claude Passeron). She then shows how she uses the tools of sociology to better adjust the courses to the audience. Finally, she sets out the limits to which this pedagogical reflexivity is confronted because of the material and institutional work conditions at the university. Far from promoting another teaching innovation, the article is intended as a modest contribution, based on personal experience, to the visibility of ordinary pedagogical work in higher education.
\end{abstract}

Keywords: Sociology teaching. Rational pedagogy. Inequalities in study conditions. University teaching. Assessment of teaching. Working conditions in higher education. 
Apresentar e analisar publicamente os princípios que norteiam a realização de um curso não é uma prática comum nas universidades francesas. A reflexão educacional sofreu historicamente com a falta de reconhecimento e há muitos sinais dessa falta de interesse. A atividade de ensino dificilmente é levada em consideração nos recrutamentos (Musselin, 2005) e aqueles que ingressam na profissão são deixados para se defender e não recebem treinamento (Hocquelet e Launay, 2009). Sobretudo recrutado como pesquisador, para o domínio de sua área de especialidade, o professor-pesquisador é esperado por causa dessa competência disciplinar de ensinar. Na opinião de muitos acadêmicos franceses, a questão pedagógica é válida apenas para os níveis de educação pré-universitária e para "novos públicos", longe da cultura escolar, e por estarem interessados demais em riscos "Secondarize" sua profissão e prejudique a autonomia do trabalho intelectual que a caracteriza (Bourgin, 2011).

Por duas décadas, no entanto, vários arranjos institucionais tentaram tornar visível e aprimorar o pensamento educacional nas universidades. Graças ao desenvolvimento de um novo campo de pesquisa dedicado à "pedagogia universitária" (Loiola e Romainville, 2008), as universidades se resumem cada vez mais no contexto da Nova Gestão Pública e na construção de um mercado. As autoridades educacionais europeias relatam sua “eficiência” (Garcia, 2008a), criaram departamentos dedicados a esta questão e lançaram pedidos de "inovação educacional”. O plano de 2007 "Licenciado com sucesso", por exemplo, resultou no estabelecimento de cursos de "metodologia universitária" e de pessoas de contato para estudantes. A pedagogia, como é reconhecida e valorizada institucionalmente nas universidades, baseia-se em dispositivos periféricos que externalizam a questão pedagógica e não a integram nas lições disciplinares que constituem o coração do treinamento. Quanto aos módulos de apoio pedagógico destinados a professores-pesquisadores, eles dizem respeito a todas as disciplinas combinadas e oferecem uma pedagogia baseada em padrões e ferramentas padronizadas, focadas principalmente no curso do curso (métodos interativos, projeção apresentações de slides etc.). Esse conceito "administrativo" de competência em ensino (Chapoulie, 1979, p. 73), tal como é realizado e definido pelos serviços especializados nas universidades, é definido transversalmente e desconectado do conhecimento disciplinar. 
Existe uma terceira via, no entanto, entre a indiferença e a institucionalização de uma pedagogia terceirizada e padronizada. Em certas disciplinas e entre as gerações mais jovens, o desinteresse pela pedagogia tende a desaparecer (Boyer e Coridian, 2001). Reflexões e experimentos educacionais são realizados, individual ou coletivamente, mas são dispersos e informais. Sem um espaço para treinamento e intercâmbio instituído, cada nova geração enfrenta a "rocha de Sísifo de invenções constantemente renovadas" (Gadéa e Soulié, 2000, p. 171). As perguntas são geralmente compartilhadas entre pares confiáveis, em ambientes amigáveis. Quando as discussões sobre o conteúdo dos cursos e seu curso ocorrem em reuniões mais formais entre colegas, elas raramente vão além da troca de planos semestrais. Vários sociólogos, no entanto, se aventuraram a colocar em público a análise de suas próprias práticas de ensino. Alguns o fizeram expondo as diferentes facetas da profissão docente em um contexto universitário (Siracusa, 2008); outros estão interessados nos efeitos e usos de determinados cursos, sejam eles palestras (Soulié, 2002; Boyer e Coridian, 2002; Duguet, 2018) ou iniciação a cursos de investigação campo (Chapoulie, 2000; Gadéa e Soulié, 2000; Jounin, 2014). Associações profissionais como a ASES (associação de sociólogos do ensino superior) reuniram e transmitiram essas questões e análises por um tempo'.

Este artigo segue a partir dessas reflexões. Ele deseja tornar visível a existência e as possíveis formas de uma reflexividade pedagógica inspirada na sociologia, questionando seus efeitos e limites. Se a pedagogia é definida como uma "teoria prática" (Durkheim, 1992, p. 79), que procede retornando à sua própria experiência para refletir sobre os meios de transmissão do conhecimento, implica uma postura de análise que é, por definição, pesquisa sociológica. Portanto, como disciplina, a sociologia oferece ferramentas heurísticas de reflexão pedagógica, mais efetivas e ajustadas do que as oferecidas pela pedagogia universitária, cuja abordagem transversal e padronizada dificilmente é um princípio de ação efetiva no campo.

A entrada escolhida é a da produção de um curso e, mais precisamente, de um curso não acompanhado de trabalhos dirigidos (TD). Na França, as aulas magistrais (CM) são historicamente a quintessência da apresentação do discurso do professor: em um

\footnotetext{
${ }^{1}$ Como evidenciado pela publicação do dossiê sobre "inovações educacionais" na carta da ASES em 1999 ( ${ }^{\circ}$ 27) e intitulado "Ensinando a não sociólogos" em 2011 (Bulletin de l'ASES, n³8).
} 
anfiteatro, o professor realiza sua aula de maneira magistral diante de uma platéia de cem alunos ou mais, deveria coletar silenciosamente conhecimento e não discuti-lo. Os movimentos de protesto de maio de 1968, que começaram inicialmente no mundo dos estudantes antes de se espalhar pelo mundo do trabalho, visavam, entre outros, a autoridade educacional. Esse questionamento levou ao desaparecimento de aulas magistrais em novas universidades experimentais como a de Vincennes e contribuiu para o desenvolvimento de trabalhos dirigidos (Damamme, 2008). Este último, destinado a um número mais limitado de alunos, visa apoiar a aula magistral aplicando-a ou aprofundando este ou aquele ponto, em um ambiente mais interativo. Essa divisão entre aulas magistrais e trabalhos dirigidos continua se estruturando no sistema universitário francês ${ }^{2}$ e é nessas formas de ensino que os textos mencionados acima se preocupam principalmente. Lições temáticas não associadas a TDs raramente são abordadas em reflexões para fins educacionais ${ }^{3}$. Mas a construção de um curso não é apenas uma questão de especialização disciplinar e conhecimento de um campo de pesquisa. Os pesquisadores-professores, diferentemente dos professores do ensino médio, têm a chance de desenvolver livremente o conteúdo de seus cursos, sem um manual imposto ou instruções oficiais (exceto em casos especiais de preparação para competições). No entanto, o desenvolvimento de um curso implica necessariamente uma seleção do conhecimento a ser transmitido - mesmo que em relação ao volume horário - e isso, longe de ser apenas uma escolha do que se enquadra " fundamentos disciplinares a serem adquiridos, levanta questões educacionais relacionadas aos objetivos e métodos de transmissão de conhecimento. Esse questionamento é válido também para as aulas temáticas ministradas no terceiro ano da licença ou no mestrado, muitas vezes ignoradas nas análises de práticas focadas nas aulas de graduação. No entanto, o aumento do nível do público não neutraliza a relevância do questionamento sobre a eficiência da transmissão e, assim como na graduação, não é suficiente expor o público estudantil ao conhecimento para ele. apropriado. As lições sem TDs associadas são, portanto, um bom

\footnotetext{
2 Essa divisão do trabalho docente tem um forte valor simbólico: por um longo tempo, apenas os professores universitários, colocados no topo da hierarquia universitária, garantiram aulas magistrais mais prestigiadas, mas também mais bem pagas (uma hora de aulas magistrais equivale administrativamente a uma hora e meia de trabalhos dirigidos).

3 Exceto nos trabalhos de língua inglesa, onde essa abordagem parece mais comum. Gary Goertz e Amy G. Mazur (2008), por exemplo, propõem em seu livro dez filhos orientadores ("dez diretrizes") para construir cursos de ciências políticas levando em consideração o gênero
} 
ponto de entrada para testar a relevância de internalizar o pensamento educacional desde o estágio de realização dos cursos.

O artigo se baseará na minha experiência como professor-pesquisador. Os cursos temáticos sem TD associado são aqueles que gradualmente assumiram um lugar cada vez maior no meu serviço de ensino (cf. caixa 1). Esses cursos têm um público que varia de quinze a sessenta alunos e esses números variáveis contribuem para seu status indeterminado: oficialmente chamados de "aulas magistrais" e sobre temas temáticos, mas ministrados diante de grupos potencialmente pequenos nas salas de aula comuns, elas escapam da divisão clássica de formas de ensino (aulas magistrais em anfiteatro / trabalhos dirigidos em pequenos grupos) e têm um formato para inventar. Esses cursos sem TD, às vezes configurados por falta de orçamento para associar um TD, não deram, no momento da construção dos modelos, reflexões específicas nas equipes de ensino envolvidas, nem do ponto de vista visão de suas modalidades ou seu conteúdo em termos de progressividade. A divisão do trabalho docente implica apenas que esses cursos temáticos devem, acima de tudo, transmitir conhecimento e não co-produzir conhecimento, fazendo com que os alunos realizem suas próprias pesquisas (prática pedagógica dedicada aos cursos metodológicos).

\section{QUADRO 1: Apresentação das aulas e de seu público}

Professor-pesquisador desde 1998, eu dei trabalhos dirigidos, como a maioria dos estudantes de doutorado, antes de me encarregar das aulas magistrais quando me tornei professor. Professor universitário desde 2013, ensino cada vez mais cursos que, sem ser "magistral" no sentido estrito, têm conteúdo temático e não são acompanhados por trabalhos dirigidos. Eles ocorreram em duas universidades parisienses, na maioria das vezes em cursos multidisciplinares, mais raramente em treinamento em sociologia (dois em cada dez). O volume horário mais frequente é de 20 ou 24 horas por semestre (exceto para dois cursos de 12 horas de mestrado). Essas lições, dez no total, focaram em vários temas. Quatro cursos, destinados a alunos de graduação do terceiro ano, têm uma audiência de 25 a 60 pessoas e são opcionais nos seguintes temas: sociologia da educação, sociologia das políticas sociais, desigualdades sociais, teorias de estratificação social. Seis outros cursos, destinados a alunos de mestrado no primeiro ou segundo ano, têm matrículas de 15 a 40 alunos e se relacionam com a sociologia das instituições judiciais, a sociologia da saúde, a 
socialização no trabalho, mudanças contemporâneas no trabalho, saúde no trabalho, desafios e atores da política social. Eu administro esses cursos para oito deles por pelo menos dois ou três anos, o que me permitiu evoluir seu conteúdo e formato ao longo do tempo.

Em relação ao público desses cursos, não tenho informações sobre sua trajetória social (o que exclui uma possível análise da relação educacional de acordo com essa dimensão, falta de dados precisos sobre esse ponto), mas os dados estatísticos das duas universidades em relação aos alunos do terceiro ano de licença em 2017 permitem comparar algumas de suas características. Nas duas universidades, 0 público é majoritariamente feminino, 68-69\%. Ele também possui três quartos do diploma de bacharel em um setor geral (e não em tecnológico, profissional ou equivalente). As diferenças entre os dois públicos são apresentadas em um nível mais refinado, por exemplo, na orientação disciplinar dos bacharelados (ciências econômicas e sociais, ciências ou literatura).

Revelar suas próprias práticas de ensino envolve auto-exposição. O que Daniel Bizeul escreve sobre os relatos de investigação de campo pode ser transposto para o professor: "Contar ao trabalho de campo [seus ensinamentos] com toda a honestidade envolve um risco: o de aparecer sob uma luz desfavorável, como um analista sem imaginação e como um investigador pobre [professor]. "(Bizeul, 2007, p. 69). Tornar públicas as perguntas pode ser interpretado como um sinal de incompetência. Outros riscos inversos aguardam o eu educacional: assim como o eu metodológico (Olivier de Sardan, 2000), ele é constantemente ameaçado de cair na complacência heróica e egocêntrica, sugerindo que receitas milagrosas podem ser encontradas. basta aplicar. $\mathrm{Na}$ esperança de evitar essas duas armadilhas da autocrítica e autopromoção, me contentarei em abrir a "caixa preta" da construção de um ensino temático e mostrar o caminho que tentei resolver, ao longo dos anos, problemas práticos relacionados aos meus ensinamentos e à sua recepção. Interessar-se pela pedagogia é mais um convite para fazer perguntas e experimentar maneiras de fazer as coisas do que uma postura que oferece soluções prontas para uso, mas a natureza situada dessas habilidades não impede que sua associação faça sentido. coletivamente. E se esse texto, por necessidade, é construído em torno de um "eu" e de exemplos pessoais, também deve muito a trocas 
informais e discretas.discretas ${ }^{4}$. Este artigo, portanto, pretende contribuir com reflexões coletivas dispersas para tornar visível a utilidade educacional de uma abordagem reflexiva ancorada sociologicamente, mas também os limites que ela encontra, e que são cada vez mais exacerbados no atual contexto de trabalho. professores-pesquisadores.

Começarei definindo minhas práticas de ensino de acordo com os dois princípios pedagógicos que me parecem organizá-los, o de uma pedagogia envolvente e uma pedagogia racional. Apresentarei os apoios educacionais que encontrei nas técnicas de pesquisa sociológica para construir e desenvolver meus cursos. Por fim, mencionarei as restrições que pesam no trabalho de ensino e necessariamente o moldam, independentemente da "boa vontade educacional" empregada.

1. Uma pedagogia envolvente

Um princípio estruturante de minhas escolhas educacionais é procurar favorecer uma estrutura « envolvente » (Darmon, 2013, p. 29), suficientemente encorajadora para fazer os alunos trabalharem. É claro que essa estrutura envolvente não pode ser comparada à que foi descrita por Muriel Darmon para os cursos preparatórios ${ }^{5}$, que consiste em assumir responsabilidade total e individualizada pela vida dos alunos (Darmon, 2013, p. 84), mas ela se aplica aqui muito bem enquanto horizonte de ação. Não deixar os alunos sozinhos para o trabalho pessoal autônomo, o que deveria caracterizar o ensino superior, sempre me pareceu uma forma evidente de reduzir as desigualdades das condições de estudo entre cursos preparatórios e universidades.

\subsection{A questão do tempo no coração do ensino}

A questão da organização e do domínio do tempo está no coração do aprendizado escolar e universitário. Em cursos preparatórios, o aprendizado urgente e pela urgência é uma das disposições a serem adquiridas (Darmon, 2013). Na universidade, o tempo de trabalho deve ser autodeterminado e o desafio é aprender a ocupar um tempo que às

\footnotetext{
${ }^{4}$ Certas trocas poderiam excepcionalmente ter uma saída pública, como foi o caso de discussões com Marie Cartier e Christelle Avril sobre nossa sociologia dos cursos de trabalho que resultaram em um livro (Avril, Cartier, Serre, 2010), incluindo a linha educacional, ou seja, a necessidade de vincular teorias e investigações empíricas é a que é defendida aqui.

${ }^{5} \mathrm{Na}$ França, os cursos preparatórios são áreas de ensino superior que preparam os alunos em um a três anos para os exames de admissão às grandes escolas (escolas normais superiores, escolas de comércio, e escolas de engenharias especialmente). Geralmente públicas e alocadas nos « lycées », eles são seletivos, ao contrário das universidades.
} 
vezes é percebido como vazio, não estruturado, e planejar o trabalho a ser feito para não concentrá-lo no final do semestre, faltando pouco para as provas parciais. O paradoxo desigual das condições de ensino entre cursos preparatórios e universidades é bem conhecido: são os alunos mais dotados que trabalham em pequenos grupos, com professores disponíveis e interessados nos casos individuais, avaliações regulares, correções, enquanto os alunos mais distantes da cultura escolar ficam por si mesmos, durante as aulas magistrais, com o emprego do tempo dividido e um trabalho escolar pouco sequenciado por causa dos exames semestrais. Todas as enquetes mostram que os primeiros ciclos na universidade fazem parte da formação que se caracteriza, ao contrário dos cursos preparatórios, por um fraco direcionamento pedagógico, um tempo livre diário importante e uma escassa quantidade de instruções e ordens de trabalho pessoal (Lahire, 2000 ; Bodin \& Millet, 2011). Em oposição aos alunos dos cursos preparatórios que são « conduzidos » pela instituição, os estudantes na universidade devem conduzir seu trabalho por conta própria, uma vez que eles e elas estão com frequência envolvidos em outras atividades quando são paralelamente assalariados (Pinto, 2010) ou por outros ritmos quando se trata de estudantes « das cidades » (Beaud, 1997) ou estudantes de área rural ou semi-rural, que voltam para suas casas todo final de semana.

Essa discrepância gera uma descrença em relação aos discursos que, em nome da autonomia do trabalho intelectual, demonstram uma atitude diletante quanto a objetivos « puramente » acadêmicos e profissionais. Enquanto a formação das elites ocorre em um contexto extremamente restrito, sem preocupação com o «interesse » dos alunos pelas disciplinas ensinadas ou com a relevância de seu projeto profissional, é deixada uma grande autonomia aos que não têm socialmente os recursos e que devem estudar por gosto e com um objetivo claro para o futuro. Como observa Charles Soulié, « o liberalismo pedagógico acadêmico, que permite que os mecanismos de auto-seleção sejam plenamente explorados, mostra-se no final particularmente "mortal" para a parte mais dominada da população estudantil » (Soulié, 2002, p. 24). Um forte desafio é, desde então, de supervisionar o trabalho dos alunos de maneira explícita e intervencionista6i ${ }^{6}$ A pedagogia envolvente consiste tanto em organizar o tempo da aula, como momento

\footnotetext{
${ }^{6}$ Este diagnóstico e este remédio não são novos e já foram feitos há vinte anos pela Association de réflexion sur les enseignements supérieurs et la recherche (Areser, 1997).
} 
chave da comunicação pedagógica, quanto o tempo entre as aulas, para que seja definido como tempo de trabalho universitário.

\subsection{Organizar e dominar o tempo durante o curso}

No coração da organização temporal das aulas se encontra o sequenciamento das sessões. Minha primeira aula temática sem TD associados, destinada a uns cinquenta estudantes de terceiro ano da licenciatura, se baseava em um plano semestral geral concebido de acordo com as normas do trabalho acadêmico, do tipo dissertação ou tese. Ele acontecia de uma sessão a outra como um pensamento se elaborando ao longo do caminho, preocupado com a exaustividade conforme muitos manuais, as partes se encadeando independentemente da duração das sessões. A introdução era longa, cheia de nuances e de referências para devidamente "colocar o sujeito » e acontecia de as subdivisões não se fecharem ao final de uma sessão e retomarem na seguinte. 0 conteúdeo - os saberes ensinados - tinham prioridade sobre os conteúdos - a colocação em forma temporal.

Ao longo de tentativas e discussões, foi necessária uma outra maneira de construir meu curso, mais adequada ao meu público-alvo de estudantes que não pretendem se tornar especialistas neste ou naquele campo. O curso agora está dividido em sessões, cada uma com sua própria consistência, e ele se apoia em uma ferramenta específica: o plano de estudos. Este é distribuído a partir da primeira sessão e especifica, para cada data, o tema que será abordado e o texto a ser lido. Essa ferramenta de planejamento não possui apenas uma dimensão técnica: como qualquer dispositivo de escrita, envolve uma modificação da atividade intelectual e cognitiva (Goody, 1979). Essa formatação por sessões requer o esclarecimento dos objetivos de cada uma delas e o destaque à sua coerência interna, sendo capaz de cortar oralmente, se necessário, passagens do curso preparado anteriormente: a principal intenção é a de tornar cada sessão uma unidade autônoma e compreensível como tal pelos alunos. Cada sessão é construída em torno de algumas idéias-chave, articuladas com conceitos e investigações precisas, e não em torno de uma busca de exaustividade sobre este ou aquele aspecto.

Esta divisão não significa, entretanto, que as sessões não tenham relação umas

com as outras e intercambiáveis em sua ordem de exposição: elas seguem uma progressão e são etapas de um raciocínio global. Por exemplo, meu curso sobre 
socializações no trabalho no mestrado de sociologia começa com sessões dedicadas às socializações profissionais mais óbvias, em formação profissional institucionalizada, antes de enfrentar situações de socialização mais informais (aprendizagem no trabalho) ou periféricas (em formações sindicais ou continuadas) e termina com sessões sobre o papel das socializações anteriores ao trabalho. Portanto, ao longo das sessões, o curso consiste em sair progressivamente do tempo e do local de trabalho, e em afastar-se das tradições sociológicas mais canônicas sobre o assunto (funcionalista, interacionista) para estabelecer vínculos com outros campos da sociologia (da educação, dos sindicatos, das classes sociais, do gênero, das gerações). É na conclusão, e não na introdução, que as questões problemáticas e as principais dissertações teóricas são retomadas e diferenciadas (socialização por inculcação /por impregnação), à luz do conjunto das pesquisas e conceitos vistos no curso. As introduções longas e problematizadas me pareceram com o tempo pouco eficazes pedagogicamente, porque os alunos se perdem nos detalhes dos prolegômenos iniciais, às vezes aprendendo-os de cor, sem hierarquizar o que importa, porque as questões, sem exemplos empíricos de apoio, Ihes parecem abstratas. A ordem pedagógica de exposição não é necessariamente a ordem lógica da dissertação ou da tese, que logo de início já define e conceitua.

O controle do tempo também envolve o pensamento sobre a sequência em cada sessão, para diversificar as seqüências dentro dela. Sem tentar formatar excessivamente o conteúdo dos cursos, escrevendo a cada minuto como certos fanáticos da "inovação educacional" promovem, tento, tanto quanto possível, variar em cada sessão o tipo de conhecimento ensinado momentos teóricos alternados (apresentação de uma tradição, definição de conceitos), conhecimento da sociedade (dados estatísticos, elementos do arcabouço institucional, jurídico, histórico) e narrativas de investigação (com apresentação dos resultados e reflexão sobre o método ) As sessões que causam menos relaxamento na anotação e maior participação oral são aquelas que obtêm sucesso nessa alternância e não permanecem em um único registro. Essa alternância entre momentos teóricos e narrativas de pesquisas é a riqueza e o interesse educacional da sociologia, mas também é o cerne do conhecimento e do raciocínio a serem transmitidos. No meu terceiro ano de graduação em estratificação social, por exemplo, não encadeio os vários autores como muitos livros didáticos (Marx, Weber, os funcionalistas, Bourdieu etc.), mas 
prefiro apenas alguns. Uso pesquisas contemporâneas como grades de leitura. A apresentação de classes sociais em Marx é assim ampliada por uma sessão sobre desigualdades econômicas contemporâneas, na qual eu complexifico e atualizo a oposição entre desigualdades ligadas ao trabalho / capital com base em dados estatísticos, antes de colocar em evidência. Hoje, graças a pesquisas de campo, desigualdades "qualitativas" mais ocultas (como as que diferenciam os compradores iniciantes de imóveis do tipo de empréstimo ao qual são designados e do relacionamento com as organizações bancárias). Portanto, preparar-se para uma lição significa pensar por sessão, por sequência, mas também não negligenciar o tempo além da lição.

\subsection{Administrar o tempo de trabalho fora do curso}

Administrar o tempo dos alunos também passa pela organização de um ritmo de trabalho regular fora da sala de aula, para estabelecer prazos semanais de trabalho ao longo do semestre. Para cada sessão, deve ser lido o texto correspondente no plano de estudos (ver Quadro 2). Essa leitura é guiada por uma grade que resume sob a forma de perguntas os reflexos a serem adquiridos na leitura de um texto sociológico: qual é o método utilizado e como os materiais são mobilizados no texto? Que perguntas o autor procura resolver? Quais são os principais resultados do texto? Quais são suas contribuições e seus limites em comparação com outros textos ou conhecimentos já vistos? Essa grade tem efeitos na escolha dos textos, que devem incluir uma dimensão empírica. A partir de agora, dou preferência a artigos de periódicos, pois eles condensam em formato curto as questões teóricas, metodológicas e os resultados. Isolar um capítulo em um livro geralmente obriga a escolher entre o capítulo que apresenta o problema e o método, e um capítulo com os resultados.

QUADRO 2: Um exemplo de planejamento curricular.

O planejamento abaixo refere-se ao curso "Socializações no trabalho ", ministrado em um mestrado de sociologia e que incluiu doze sessões de duas horas. Além da qualidade pedagógica do artigo (mobilização explícita do material de campo, clareza da redação e da demonstração), outros critérios orientam a escolha dos textos. 0 primeiro é a preocupação de variar os mundos profissionais e grupos sociais estudados: agricultores, executivos do setor público (juízes, oficiais do exército, médicos do hospital) e do setor privado (engenheiros), funcionários (agentes administrativos de prefeituras, 
guardas de edifícios, funcionários de hotéis de luxo, guardas prisionais) e operários (na indústria automobilística e em estaleiros). Os outros critérios são o gênero dos autores (tantos homens quanto mulheres) e a diversidade de periódicos (especializados em sociologia do trabalho ou generalistas).

Sessão 2. A abordagem funcionalista da socialização profissional.

Anne Boigeol, "Qual direito para qual magistrado? Evolução do lugar do direito na formação dos magistrados franceses 1958-2005 ", Droit et société, $2013, n^{\circ} 83$

Sessão 3 .. A abordagem interacionista da socialização profissional

Guillaume Malochet, "Na escola de detenção: alguns aspectos da socialização profissional dos vigias prisionais", Sociologie du travail, 2004, 46 (2)

Sessão 4. A influência da forma escolar na formação profissional.

Julien Bertrand, Christel Coton, Sabrina Nouiri-Mangold, "Escolas de excelência fora da escola. Oficinas de formação e ranking escolar ", Sociétés contemporaines, 2016, $n^{\circ} 102$

Sessão 5. Socializações informais no trabalho e aprendizados no trabalho.

Robert. Linhart, L'ablabli, Paris, Minuit, 1978, capítulo 1

\& Alexis Spire, "O asilo no balcão. A despolitização dos direitos dos estrangeiros através do trabalho burocrático ", Anais da pesquisa em ciências sociais, 2007, $n^{\circ} 169$

Sessão 6. Ressocializações profissionais em educação continuada e treinamento sindical.

Hélène Stevens, "Autonomia recusada, autonomia fabricada. Cientistas da computação enfrentando o teste da auto-empresa ", Genesis, 2012, $n^{\circ} 87$

Sessão 7. Trajetórias sociais $e$ ingresso na profissão. Hereditariedade profissional e « vocação »

Céline Bessière, "Uma profissão de família: as três dimensões da vocação agrícola", em Florença Weber et al., Charges de famille, La Découverte, 2003

Sessão 8. A articulação das socializações primárias e secundárias.

Hervé Marchal, "Os cuidadores de edifícios: o presente combinado com o passado", Formação emploi, 2007, n 97.

Sessão 9. O peso das socializações geracionais.

Emilie Biland, "Transformações geracionais da politização nas autoridades locais", Politix, 2011, $n^{\circ} 96$

Nicolas Roinsard, "Entrando nos Chantiers: as transformações da socialização profissional e das relações intergeracionais nos Chantiers de I 'Atlantique (1950-2005)", Sociologie du travail, 2012, 54 (2)

Sessão 10. O peso das socializações de gênero.

Emmanuelle Zolesio, "Mulheres na profissão de homem: aprendendo sobre cirurgia", Trabalho, gênero e sociedades, 2009, $n^{\circ}$ 22

Sessões 11. Socializações no trabalho e práticas fora do trabalho. 
Amélie Beaumont, "Gorjeta e aula. Dinheiro e posição social entre funcionários de hotéis de luxo ", Genesis, 2017, n 106

Essas leituras preparatórias dão lugar a uma retomada em cada sessão, que geralmente dura entre 15 e 30 minutos (mais de duas horas). Essa sequência começa com uma discussão que começo com perguntas amplas (o que você reteve do texto? O que você gostou ou não?), Para legitimar qualquer resposta e incentivar o fato de ter lido o texto, mesmo que rápida e parcialmente. Não deslegitimar imediatamente as práticas de leitura “cortadas, descontínuas, informativas, rápidas" (Lahire, 2002, p. 103) me parece importante, mesmo que o objetivo final seja a aquisição de habilidades de leitura que atendam às expectativas da universidade.

Essas leituras regulares não dão origem a avaliação imediata. Eles servem como muletas para o trabalho pessoal de estudantes que desejam preparar ou retomar o curso e não sabem como fazê-lo. O desafio não é deixá-los se defender diante de uma bibliografia rica em obras não hierárquicas. Esse momento interativo também corresponde à preocupação de variar as seqüências dentro do curso para manter a atenção e, além disso, é investido pelos alunos quando chega no meio da sessão entre duas aulas magistrais. Termina com uma retomada que resume as respostas à grade inicial e que me permite igualar o conhecimento entre os alunos, independentemente da leitura real do texto.

Essa estrutura que incentiva o trabalho regular permanece, no entanto, não muito constrangedora, tanto que não está associada a uma questão de classificação escolar. Por isso, gradualmente, tentei associá-lo ao modo de avaliação no contexto de uma pedagogia racional.

2. Uma pedagogia racional

\section{1. a exigência de explicitação}

No final de Héritiers (1964), Pierre Bourdieu e Jean-Claude Passeron definem de maneira programática as diretrizes a seguir para estabelecer os fundamentos de uma pedagogia verdadeiramente democrática, permitindo que o maior número de indivíduos se apodere da habilidades que compõem a cultura escolar a qualquer momento. Essa 
pedagogia racional é concebida como uma maneira de otimizar o desempenho da comunicação pedagógica, evitando qualquer perda. Designa o ajuste ideal entre a quantidade de informações enviadas (pelos professores) e a quantidade de informações recebidas (pelos alunos). A racionalidade da pedagogia, por cumprir um objetivo de eficiência, torna possível perseguir um objetivo de eqüidade. Se essa preocupação com "desempenho educacional" soa estranha cinquenta anos depois, em um contexto de avaliação por objetivos cada vez mais significativo, o olhar retrospectivo não deve nos fazer esquecer o poder de ruptura desse problema no momento em que a indiferença às questões de recepção da educação permitiu que os mecanismos de seleção, de acordo com o capital cultural incorporado, atuassem ao máximo. Nesta área, como em outras, o espírito neoliberal conseguiu endogenizar e neutralizar as críticas sociais (Boltanski e Chiapello, 1999). A preocupação com a eficiência em questão aqui deve ser entendida em seu sentido original e seu objetivo de democratização e não em seu sentido gerencial.

O princípio no centro da pedagogia racional é que os professores devem "vender o pavio", ou seja, não tratam a metodologia com desprezo e explicam todo o conhecimento a ser dominado para não confiar no conhecimento externo e implícito adquirido na esfera familiar. A explicação do implícito também se relaciona com o conhecimento mínimo a saber sobre os métodos de trabalho a serem implementados para adquiri-lo. Para evitar a eliminação arbitrária das classes trabalhadoras e reduzir a desvantagem dos mais desfavorecidos (isto é, os mais distantes da cultura escolar), a pedagogia racional consiste em oferecer um curso acessível e "lucrativo", com um conteúdo facilmente apropriado (Bourdieu, Passeron e de Saint Martin, 1965, p. 99). Uma questão central é, portanto, "delimitar e definir o que é necessário racionalizando o exame", reduzindo o papel de formas e conhecimentos difusos e organizando continuamente o exercício (Bourdieu, Passeron e de Saint Martin, 1965, p. 30). O objetivo de passar nos exames e a questão de como o conhecimento deve ser avaliado devem, portanto, ser levados a sério e não são secundários .

O requisito da explicitação não pode, contudo, ser traduzido em uma prática de ensino única e estável. Como Pierre Bourdieu e Jean-Claude Passeron nos lembram, a

\footnotetext{
7 Ao contrário, acreditar que suprimir o exame é suficiente para renovar o relacionamento educacional e tornar o ensino acessível a todos é ilusório, como mostra a análise do ensino de filosofia na universidade experimental de Vincennes (Soulié, 2018).
} 
pedagogia racional é aquela que melhora a comunicação pedagógica, garantindo o máximo ajuste a uma dada população: nenhuma técnica de transmissão tem "virtudes ou vícios intrínsecos", tudo depende características sociais e educacionais do público (Bourdieu e Passeron, 1970, p. 127). A pedagogia racional não se baseia em uma racionalidade universal que seria uma questão de encontrar e aplicar de uma vez por todas: é acima de tudo uma postura que visa a transparência com o objetivo de uma melhor comunicação pedagógica. Transparência em relação a si mesmo como professor, que pressupõe uma postura reflexiva nas próprias práticas, e transparência em relação aos alunos a quem se trata de explicar as expectativas.

\subsection{Preparar-se para o exame continuamente}

A pedagogia racional implica o esclarecimento das ferramentas de trabalho que podem ser mobilizadas. Essas ferramentas, que também participam da estrutura envolvente mencionada acima, são suportes importantes para a explicação. Assim, distribuo, no início do semestre, uma brochura que inclui, além do planejamento das sessões com o tema e o texto associado, uma bibliografia geral (alguns manuais e sites de recursos), instruções para a avaliação final, os textos ler, a grade de perguntas para lê-los, materiais de apoio para o curso (tabelas estatísticas, textos de leis, definições). Este documento de trabalho semestral é completado durante as sessões. Um documento muito apreciado pelos alunos é uma folha que distribuo no início de cada sessão, como um programa, e que inclui o plano detalhado da sessão e a bibliografia dos textos que serão mencionados. Este documento facilita o trabalho de anotações dos alunos, ajuda-os a seguir o curso visualizando seu progresso e facilita as revisões, materializando o conhecimento a ser aprendido.

Uma questão central da pedagogia racional é a questão dos exames. É uma grande dificuldade para os cursos sem TD, que não passam por um controle contínuo, para estabelecer um vínculo entre o trabalho regular de leitura, o curso e o exame. Como fazê-los trabalhar regularmente se o exame só acontece no final? E como não desmobilizar se a nota chegar e não houver mais questões escolares para seguir os últimos cursos? Quando uma tarefa sobre a mesa era exigida pelos regulamentos dos testes de conhecimento, experimentei vários tipos de exames: dar um assunto a partir de uma citação de um dos textos lidos que deveria ser contextualizado antes de discutir; 
propor um tema de síntese com obrigação de tratá-lo com dois textos lidos no semestre; fazer perguntas distintas, uma sobre o curso e a outra sobre um texto.

No momento, aproveito o fato de que a regulamentação do teste de conhecimento não me impõe mais uma atribuição de tabela para experimentar um novo método de avaliação. Percebi que o exame em sala de aula tende a superestimar a questão da memorização, pois o primeiro requisito é restaurar o conhecimento aprendido da memória. Essa questão impede o desenvolvimento de outra habilidade essencial, a saber, a capacidade de mobilizar o conhecimento mais adequado à questão e articulá-lo entre si para construir um argumento. Então, testei uma nova maneira de avaliar o desempenho dos alunos. Eu distribuo no início do semestre o texto que serve de suporte para a discussão-comentário que eles e eles devem retornar para mim na penúltima sessão (para que eu possa devolvê-los os corrigidos na última sessão) (cf. caixa 3) Esta tarefa deve incluir uma parte da análise do texto de acordo com os mesmos requisitos praticados a cada semana e uma parte da discussão, de acordo com os eixos escolhidos livremente, mas relacionados ao conhecimento visto nas aulas e nos textos lidos. Cada sessão, portanto, potencialmente enriquece a tarefa final e abre novas perspectivas para reflexão (mesmo que propondo métodos de pesquisa diferentes dos adotados no texto estudado). A tarefa é escrita com as notas do curso e os textos disponíveis, de modo que o desafio não é mais a memorização, mas a identificação do conhecimento para se relacionar efetivamente. Experiente em duas lições, este dispositivo se mostrou convincente: as tarefas eram mais ricas e bem mais discutidas do que as tarefas habituais de mesa, porque os alunos se arriscavam mais a se mobilizar e combinar seus conhecimentos para defender seu ponto de vista na parte livre de seu comentário.

QUADRO 3: ois tipos de avaliação para um mesmo curso.

Em relação ao curso cujo currículo foi apresentado acima (caixa 2), dois tipos de avaliação foram testados, sempre com o objetivo de estabelecer a ligação entre leituras regulares, todo o curso e a exercício proposto. No primeiro caso, a avaliação consiste em uma tarefa em cima da mesa durante a última sessão. O assunto é baseado em uma citação extraída de um dos textos do currículo lidos durante o semestre e explica os pontos problemáticos a serem 
desenvolvidos. No segundo caso, o assunto é abordado desde a primeira sessão, mas é limitado a um texto que se trata de comentar e discutir, de acordo com faixas problemáticas escolhidas livremente de acordo com os temas abordados nas aulas ao longo do semestre.

Primeira avaliação : tarefa sobre a mesa. Exemplo de assunto :

Em seu artigo intitulado "Les gardiens d'immeubles: le présent conjugué au passé », publicado na revista Formation Emploi en 2007, Hervé Marchal escreve :

"Parece que os graduados, os "novos" guardas, são mais capazes de reivindicar seu pertencimento ao mundo HLM (habitação de locação moderada) devido à sua passagem por cursos de treinamento. Sendo a socialização profissional mais sólida que a dos "empiristas", eles parecem mais burocratizados porque conhecem a lógica gerencial. Mas aqui novamente, é necessário considerar o fato de que os "diplomados" (os graduados) também enfrentam dificuldades reais para não se desapegar das instruções formais, na medida em que o bairro representa um cenário local que exige diariamente o enfrentamento para inúmeras situações. É por isso que a identidade estatutária sempre parece estar em concorrência com identidades informais indexadas às contingências da área. ».

Vocês devem explicar e discutir esta citação para refletir, com base em seus conhecimentos, sobre como uma socialização profissional « sólida » pode ou não ser substituída por identidades ou socializações informais..

Segunda avaliação : tarefa de casa. Exemplo de assunto :

O dossiê consiste em um comentário e uma discussão do seguinte texto:

P. Guibert, G. Lazuech et F. Rimbert, Enseignants débutants : “ Faire ses classes ». L'insertion professionnelle des professeurs du second degré, Rennes, Presses Universitaires de Rennes, 2008, p. 10 13 et p. 131-160 (Chapitre 7 "Consolidation professionnelle»)

Este dossiê deve ter duas partes: uma parte de apresentação e de análise do texto, e uma parte de discussão e de colocação em perspectiva.

Na parte de análise vocês devem identificar:

a problemática, as perguntas feitas, os trabalhos ou as tradições sociológicas que inspiram o texto (ou aos quais ele se opõe) o material sobre o qual o texto se apoia, a forma pela qual ele foi coletado (método utilizado, postura dos autores) e a maneira pela qual este material empírico é mobilizado e apresentado na argumentação

os principais resultados.

Na parte da discussão vocês devem :

refletir sobre o valor da demonstração (administração da prova convincente ou não; limites eventuais)

colocar em prespectiva o (os) método(s) utilizado(s) com 
outras abordagens possíveis e explicar o que o dispositivo de pesquisa escolhido permite ver ou ao contrário o que ele torna invisível

colocar em evidência as contribuições ou os limites deste texto em relação às diferentes perspectivas problemáticas vistas no curso e outros resultados de pesquisa. Esta comparação os levará a propor outros questionamentos e outros tipos de investigação possíveis para aprofundar a análise da socialização dos professores.

A análise e a discussão devem se apoiar, com a maior frequência possível, sobre os conhecimentos adquiridos no curso para precisar e aprofundar a proposta (definições, estatísticas, conceitos teóricos, enquetes). 0 dossiê deve mobilizar de forma obrigatória pelo menos três textos entre os estudados no curso. As referências bibliográficas nas notas de rodapé devem ser precisas e todas as citações extraídas dos textos devem ser referenciadas com o número da página.

\section{A abordagem sociológica a serviço da pedagogia}

Na busca por melhorar a transmissão pedagógica, o saber sociológico não é apenas um conhecimento disciplinar, distinto do "conhecimento da experiência » (Deauvieau, 2007, p. 108): ele representa um papel importante como conhecimento reflexivo, porque fornece ferramentas para refletir sobre os efeitos de suas práticas de ensino e para fazê-las evoluir.

\subsection{Levar em conta as expectativas dos estudantes}

A questão do ajuste e da transparência está - como vimos - no centro da pedagogia racional. Para identificar as expectativas e realizações dos alunos, passo na primeira sessão um questionário relacionado ao seu passado acadêmico (curso desde o bacharelado, curso específico do tipo Erasmus, cursos já realizados em relação ao tema do curso) e suas expectativas (estudos e / ou projetos profissionais, motivos para a escolha do curso, se for opcional, temas nos quais estão particularmente interessados). Essas folhas não incluem perguntas sobre a trajetória social e não visam o conhecimento individual de um aluno em particular - com todos os vieses potencialmente desfavoráveis que isso pode gerar na classificação (Merle, 2007). As informações puramente acadêmicas que eles contêm desempenham o papel de proxy do conhecimento realmente possuído pelo grupo no início do semestre, a fim de determinar o nível de explicitação a ser adotado e os pontos a serem desenvolvidos. Por exemplo, a recorrência 
de um interesse em desigualdades educacionais nas razões para escolher meu curso sobre desigualdades, quando pensei que esse tópico já era bem explorado e conhecido, me convenceu a insistir nele um pouco mais do que o que eu tinha planejado originalmente. Por outro lado, sabendo que os alunos do terceiro ano de graduação, matriculados no curso opcional de sociologia das políticas sociais, não desejavam se tornar assistentes sociais, ao contrário do que eu havia antecipado, me incentivavam a não indo muito longe nos detalhes de dispositivos e leis e favorecendo as relações com outros campos da sociologia.

Outras ferramentas, como o mapa semântico, podem desempenhar esse papel de aproximação. No mesmo curso sobre políticas sociais, na primeira sessão, peço a cada aluno que associe uma ou duas palavras ao termo políticas sociais. Observo suas respostas à mesa como e quando elas são agrupadas implicitamente por atores (fundos de seguridade social, Estado, associações, hospitais, etc.), benefícios (renda solidária ativa, abonos de família etc.), princípios (solidariedade, equidade etc.), áreas de intervenção (pobreza, velhice, saúde etc.). Esse mapa semântico estabelecido coletivamente me permite explicar suas representações, identificar as omissões (tal ator, tal domínio...) e destacar as diferentes entradas possíveis para pensar em políticas sociais.

Essas diferentes ferramentas, questionário e mapa semântico, visam identificar as expectativas e os conhecimentos dos alunos para melhor se ajustarem a eles. Eles evitam a construção do ensino apenas com base em um nível supostamente adquirido e ajudam a compreender o implícito a ser esclarecido. Esses desvios permitem uma suspensão de suas próprias categorias intelectuais e professores, remanescente dos esforços a serem feitos, em qualquer pesquisa sociológica, para entender a lógica específica e singular do grupo que se deseja estudar.

\subsection{Coletar as percepções dos estudantes por questionários}

Para entender a recepção do curso, além das únicas avaliações do conhecimento adquirido, também coleto, na última sessão, as opiniões dos alunos. Como na primeira sessão, faço isso por escrito para coletar as percepções de todos, não apenas daqueles que se sentem mais à vontade para falar e se permitem responder ${ }^{8}$. No entanto, ao

\footnotetext{
${ }^{8}$ Os questionários passados em sala de aula têm a vantagem de ter uma taxa de resposta de $100 \%$ em comparação com os passados on-line pela universidade, que têm taxas de resposta muito baixas (apenas 10
} 
contrário do primeiro questionário, este é anônimo. O objetivo desse anonimato é remover os efeitos da censura e liberar a fala.

Essa grade final de avaliação mobiliza o know-how específico para a construção de qualquer questionário sociológico. As perguntas tiveram que ser mais precisas, para não se obter mais opiniões muito acadêmicas e gerais. É realmente surpreendente ver com que facilidade os alunos reproduzem a postura de avaliação do ensino («curso interessante ») se lhes fizerem uma pergunta muito vaga (o que você achou do curso?). Por isso, fui inspirado pelas técnicas usuais de questionário em sociologia para não impor qualquer problemática e evitar respostas absurdas: dou preferência a perguntas concretas e precisas sobre o ritmo, por exemplo, pergunto aos alunos sobre cada tipo de exercício (leitura regular, tarefa final) para saber se acharam fácil ou difícil, e peço a opinião deles sobre este ou aquele texto, este ou aquele capítulo, apresentando-Ihes o esboço e os textos do conteúdo programático para despertar suas lembranças. Mesmo que nenhum aluno dê uma opinião sobre todas as sessões, isso lhes estimula, apesar de tudo, a se expressar sobre as que lhes marcaram, negativa ou positivamente. Deixo também a possibilidade de uma resposta « não se aplica » (curso não seguido / texto não lido) para evitar opiniões falsas causadas por um « dever de responder » (Gaxie, 1990, p. 103). O objetivo é questionar práticas reais e ter opiniões construtivas. Esse método de coleta de opiniões dos alunos é, portanto, muito diferente das grades de avaliação padronizadas propostas pela universidade, que devem funcionar para todos os cursos, seja qual for a disciplina e o conteúdo, com perguntas do tipo: «Este ensino lhe interessa? » ou « Você considera este ensino útil para a sua formação? ».

Só uso perguntas abertas porque elas dizem mais para uma possível retomada do ensino. As avaliações numéricas são completamente inúteis para direcionar a ação: uma alta taxa de insatisfação não diz nada sobre a fonte da insatisfação, enquanto uma observação crítica, mesmo que seja minoritária, pode atrair a atenção construtivamente para um problema. Esses questionários de avaliação ad hoc são afinal um bom suporte como no caso do «questionário etnográfico » (Soutrenon, 2005) - para se envolver em discussões coletivas - até contraditórias - com os alunos. Não é incomum que, uma vez

alunos de 64 responderam à pergunta. pesquisa on-line de um dos meus cursos). A baixa taxa de participação é um problema recorrente do "EEE" (avaliação de ensino pelos estudantes) vivenciado pelos serviços pedagógicos (Heyde, Le Diouris, 2009, p. 65-66). 
preenchido o questionário, eles e elas se permitam falar oralmente e comecem a trocar informações sobre esse ou aquele ponto. Poi, se a forma escrita permite uma expressão mais livre graças ao anonimato, a forma escritural não imporá menos para os alunos convocados a dar uma opinião sintética e abstrata sobre o conteúdo e o desenrolar de um curso sendo que, às vezes, suas categorias de apreciação se referem mais espontaneamente com o professor (simpático, severo etc.).

As avaliações dos alunos me motivaram, por exemplo, a mover certos capítulos históricos, para deixar claro que a história não era uma passagem cronológica obrigatória, mas um desvio útil para esclarecer uma questão contemporânea. O feedback dos alunos confirmou o interesse do plano de estudos, mapas e bibliografias específicos, que são ferramentas de enquadramento elogiadas por unanimidade. Mas os alunos também apreciam ter uma margem de liberdade, por exemplo, para desenvolver sua reflexão pessoal de acordo com eixos que eles determinaram livremente no comentário de texto, como evidenciado pelas seguintes avaliações: « $A$ abordagem do DM e a liberdade que tínhamos em lidar com a parte tornaram essa atividade agradável. O fato de ser pertinente a todos os aspectos estudados em aula se tornou uma excelente conclusão. » «Acho o conceito [de tarefa de casa] muito interessante, pois permite analisar o texto com os conceitos e teorias vistos nas aulas, e também dar sua própria reflexão pessoal. »

A idéia dessas avaliações não é, então, de entrar em uma lógica consumista em que os estudantes pudessem escolher seu curso à la carte. Essa avaliação qualitativa e autodeterminada, que permanece nas mãos do professor em questão, não tem nada a ver com a avaliação imposta de cima, como parte de uma «abordagem de qualidade » pensando em usuário como cliente e professor como um prestador de serviços (Garcia, 2008b). O desafio é identificar as ferramentas pedagógicas mais eficazes (este texto, esta entrada) e as mais capazes de convencer e mobilizar.

\subsection{Manter um registro da recepção nas anotações de campo}

Um outro saber sociológico útil para a reflexividade consiste em manter um diário de campo sobre os cursos realizados. Não estou pensando aqui em um diário de campo em boa e devida forma, contando nos mínimos detalhes o desenrolar dos cursos, mas em anotações feitas com frequência para registrar os eventos mais significativos e instrutivos para uma retomada no ano seguinte (se houver retomada). Assim, anoto meu curso logo 
após tê-lo feito para indicar o tempo gasto em cada parte, as passagens que não foram tratadas (ou ao contrário, que desenvolvi sem ter previsto), as perguntas pertinentes ou surpreendentes que me foram feitas, as reações quanto ao texto a ser lido (« funcionou bem », «agradou» ou "precisa mudar»). Essas anotações rápidas são úteis para identificar os ajustes a serem feitos para o próximo curso ou no ano seguinte. Por exemplo, observei a reação de um aluno que ficou surpreso com a maneira como propus uma tipologia de paradigmas teóricos dentro da qual classifiquei os autores, depois de explicar os limites das análises procurando fazer uma tipologia de usuários. No ano seguinte, eu apresentava as coisas de maneira diferente, insistindo em sistemas de oposição que poderiam se cruzar e se articular nas análises e nas pesquisas (usuário dominado / usuário estratégico, explicação através do contexto / explicação por provisões). Em outro curso sobre saúde ocupacional, dirigido a alunos do segundo ano de mestrado, muitos dos quais estavam retomando os estudos, anotei as numerosas perguntas que me foram feitas sobre Prudhommes, um tema que, ausente do programa inicial, provou despertar grande interesse e que, para minha surpresa, era completamente desconhecido deles. Essas anotações no modo do diário de campo, como as avaliações dos alunos, são um recurso importante para decidir quais textos manter ou não na apostila e para adaptar o curso de um ano para o outro.

Adequação ao público, questionários, anotações de campo, são os tantos pontos de apoio extraídos da abordagem sociológica, que permitem desenvolver uma reflexividade pedagógica com a intenção de melhorar a transmissão. No entanto, essas ferramentas também abrem inúmeras perguntas e enfrentam restrições.

4. Práticas pedagógicas sob restrições

Mesmo que pesquisas recentes mostrem que as práticas de ensino, particularmente na organização do curso, têm um efeito significativo no sucesso da universidade, essas práticas têm um impacto menor do que o passado acadêmico dos estudantes (Duguet 2015). Além disso, desde o início, a capacidade de reforma da pedagogia racional foi debatida. Os próprios Pierre Bourdieu e Jean-Claude Passeron, seis anos após a publicação dos Heirs, estimaram em La Reprodução que essa solução era "utópica" (1970, p. 69) se não fosse acompanhada por transformações reais no 'organização de estudos. Essa visão, percebida como fatalista, tem sido amplamente 
criticada por atores comprometidos com a reforma educacional, particularmente dentro do principal sindicato de professores (Masson, 2005, p. 89). Para Pierre Bourdieu, no entanto, não era tanto fatalismo quanto realismo: ele nunca desistiu de trabalhar pela democratização do sistema educacional e investiu regularmente em propostas abrangentes de reforma. De fato, a implementação de uma pedagogia racional e envolvente, para fins democráticos, enfrenta um certo número de restrições estruturais e sua eficácia permanece limitada pelo contexto em que ocorre.

\subsection{A heterogeneidade do público}

A heterogeneidade dos alunos no final de seus diplomas de bacharelado e mestrado é menor do que nos primeiros anos da universidade, mas permanece forte, mesmo que apenas devido à diversidade de carreiras anteriores e ao conhecimento adquirido em sociologia [cf. caixa 1 acima]. Essa heterogeneidade do público é acentuada pelo desenvolvimento de modelos "à la carte", nos quais os alunos têm mais e mais cursos opcionais e onde são desenvolvidos cursos compartilhados entre os campos, a fim de economizar no orçamento. Nesse contexto, é raro haver uma promoção com rotas aproximadamente semelhantes e identificáveis. A bagagem comum sobre a qual se inclina diminui e a progressividade de um ano para o outro se torna ilusória.

Esta heterogeneidade das trajetórias explica por que as avaliações dos alunos estão longe de resolver todos os problemas e contribuem também para alimentar as perguntas. $\mathrm{O}$ contraste entre as apreciações é frequente ${ }^{9}$ e a diversidade de opiniões sobre o mesmo curso às vezes é desconcertante. Um mesmo ensino pode ser julgado como sendo muito rápido ou muito lento. Essas opiniões contraditórias me permitiram entender os limites da técnica que consiste em reformular a mesma idéia com palavras diferentes, para que todos possam se apropriar da fórmula que mais lhes fale. Essas reformulações dão a sensação, para os que seguem, de que o curso se repete e aumentam o desconforto daqueles que estão perdidos e que tentam anotar tudo para se tranquilizar, sem nunca conseguir anotar uma única explicação integralmente. Uma maneira de superar essa aporia é sinalizar claramente os momentos de retomada (« colocando de outra maneira »), diminuindo o ritmo para permitir anotações completas

\footnotetext{
9 Tania Angeloff et Céline Bessière (2014) fazem a mesma observação em relação ao ensino de gênero: seja qual for sua escolha pedagógica, as opiniões dos alunos permanecem contraditórias a cada ano em uma mesma promoção.
} 
pelo menos uma vez. O fato de ter o plano detalhado à sua frente também é considerado como uma ajuda real para fazer anotações, pois tranquiliza e limita a sensação de "perda », como aparece em algumas avaliações dos alunos: «o plano permite avançar rapidamente, tendo um conteúdo denso »; « Um ritmo intenso, mas seguir um plano préestabelecido permite que você siga sem dificuldade. Portanto, não é perturbador »; «O ritmo às vezes é um pouco sustentado, mas o curso é organizado, o que facilita a sua compreensão ». Entretanto, essas diferentes técnicas pedagógicas não são suficientes para igualar as capacidades de compreensão dos alunos, pois a divergência de expectativas quanto ao ritmo do curso depende em grande parte do tipo de baccalauréat obtido (Soulié, 2002, p. 30) e da trajetória escolar anterior.

\subsection{As restrições materiais e temporais}

Com seus efeitos limitados devido às características do público, o trabalho pedagógico também deve enfrentar muitas restrições materiais e de tempo que, muitas vezes ignoradas pelos promotores de «inovações educacionais », pesam, no entanto, fortemente nas condições de possibilidade de manutenção de uma preocupação educacional.

Uma primeira restrição se deve à carga horária dos cursos que não cessaram de diminuir, primeiro com o desaparecimento dos cursos anuais e a transição para a semestralização, depois com restrições orçamentárias que gradualmente impõem reduções de $10 \%$ ou $20 \%$ da carga horária nos modelos (um dos meus cursos passou de um ano para o outro, de 39 horas para 24 horas). Diante dessa redução no horário de ensino, manter o requisito de explicitação implica fazer escolhas temporais que restringem ainda mais a massa de conhecimentos expostos. Existe, portanto, uma grande tentação de não se tomar tempo voltando à metodologia ou discutindo os textos, a fim de «avançar » no curso. Os momentos interativos são aqueles que tendem a desaparecer primeiro em uma situação de pressão de tempo. No entanto, seu encurtamento costuma ter efeitos imediatos, por exemplo, na boa vontade dos leitores. A experiência mostrou que, mesmo que poucos alunos consigam acompanhar a taxa de leitura semanal até o final do semestre, um fator importante em sua tenacidade reside na organização do próprio curso: se eu não usar tempo suficiente para discutir o texto e me contente em resumi-lo, 
eles e elas perdem rapidamente o interesse em lê-lo. O quadro envolvente funciona apenas se for mantido e suportado.

Da mesma forma, o número e a qualidade das classes jogam nas possibilidades de trocas. Discutir textos de maneira mobilizadora para todos é menos fácil em uma turma com cinquenta alunos, em uma sala com isolamento acústico, do que em uma turma de vinte. As salas com cadeiras aparafusadas ao chão, que impedem os alunos de se virarem para os colegas quando falam, reforçam a tendência de falar apenas com o professor e incentivam o auditório a não lhes responder e a aguardar o professor para saber o que anotar no texto.

Finalmente, a operação de reprografia é de importância crucial. Ser capaz de depositar apostilas ou ter planos detalhados reproduzidos alguns dias antes da sessão, e sem limitação do número de páginas, é uma condição necessária e essencial para a distribuição regular de materiais eficazes de apoio ao curso. De fato, novamente, por razões de economia orçamentária, certos departamentos reservam as apostilas apenas para os TDs e estabelecem um número máximo de páginas a serem respeitadas (80 páginas para o semestre, por exemplo). Essas escolhas orçamentárias, geralmente acompanhadas do incentivo para depositar os documentos do curso no site da Universidade, devem ser pedagogicamente neutras. No entanto, sem querer justificar excessivamente o que também é uma questão de hábitos geracionais, o arquivamento on-line não me convence se ele substitui completamente o papel porque se depara com desigualdades no acesso ao site (uma avaliação que eu fiz um ano havia mostrado que pouquíssimos estudantes procuravam os planejamentos que eu colocava online). A vantagem de uma versão em papel é que ela pode ser anotada em aula e garante que cada um saia, ao final da sessão, com uma documentação completa sobre ela (notas, plano, bibliografia).

As restrições materiais não estão ligadas apenas ao ambiente físico e organizacional dos cursos. Planejar o trabalho de outras pessoas tem um revés às vezes difícil, que é o planejamento rígido do seu próprio trabalho. Colocar uma restrição de tempo no trabalho dos alunos também implica uma forte autocontrole. É óbvio que todos os dispositivos mencionados acima, formalizando o planejamento ou a distribuição de planos detalhados durante a sessão, são difíceis de manter quando as aulas são 
preparadas no prazo curto e não podem ser suficientemente antecipados, o que acontece com frequência no primeiro ano em que são concluídos, por exemplo, mas também quando há muitos cursos para gerenciar ao longo do semestre ou no mesmo dia. Mesmo que eu esteja convencido dos benefícios de um controle temporal de perto, também às vezes me acontece de não seguir à risca por falta de tempo. O ensino é apenas uma faceta da atividade de professores e pesquisadores e está constantemente em concorrência com outros investimentos de tempo possíveis ou restritos. O trabalho pedagógico às vezes funciona como variável de ajuste em um contexto de intensificação do trabalho e de acumulação de tarefas novas e diversas, principalmente administrativas (Faure, Millet et Soulié, 2005).

\section{Para concluir}

As práticas e as reflexões pedagógicas aqui expostas são baseadas apenas em alguns exemplos pessoais, vinculados a um contexto de ensino específico (cargas horárias reduzidas, formações pluri-disciplinares em que o gosto pela sociologia não é natural) e elas exigiriam « ser esclarecidas, criticadas, enriquecidas pelas experiências de uns e de outros ${ }^{10}$. Elas parecem sem dúvida banais para quem já tem bastante experiência neste tipo de questionamento, principalmente porque os ensinamentos apresentados não propõem inovações espetaculares, seja em matéria de usos numéricos ou do questionamento da relação pedagógica e da postura de educador detentor do conhecimento. Mas o desafio era justamente o de mostrar como a sociologia pode inspirar uma reflexividade pedagógica ordinária que, apesar de seus limites, é bem mais ajustada aos contextos de ensino e aos conteúdos disciplinares do que a pedagogia universitária, com frequência padronizada e avaliadora.

Essa reflexividade pedagógica de inspiração sociológica me levou, ao longo do tempo, a estruturar minhas práticas de ensino em torno de dois princípios. O primeiro, que chamei de « pedagogia envolvente » em referência à estrutura envolvente dos cursos preparatórios (Darmon, 2013), consiste em construir um prazo claro para os alunos, um

\footnotetext{
10 Os exemplos de extensões extraídas das experiências dos colegas são numerosos, sejam eles relacionados a inovações em seqüências interativas (trabalhando em grupos em um documento), o incentivo para trabalhar regularmente (MCQs rápidos em textos lidos a cada semana), avaliações. cursos de estudantes (coletados regularmente através da plataforma interativa da universidade), as ferramentas de trabalho oferecidas (folhas lexicais) ou as formas de exame (várias disciplinas na forma de tweets dados previamente que é desconstruir e discutir).
} 
suporte essencial para o seu trabalho. Essa organização do tempo ocorre a nível do semestre, dividido em sessões identificadas por objetivos de trabalho e de textos; ao nível do curso, seqüências alternadas de aulas magistrais e de momentos mais interativos, conhecimentos teóricos e relatos de enquetes; e, finalmente, em termos de tempo fora da aula, a ser ocupado por exercícios de preparação e aprofundamento. O segundo princípio, o da «pedagogia racional », retoma a preocupação, cara a Pierre Bourdieu e Jean-Claude Passeron (1964), de explicar os implícitos. Pressupõe variações de registros de linguagem e de formulações, no fornecimento de ferramentas de trabalho, no esclarecimento dos requisitos do exame e na preparação contínua deste último (com correções regulares e uma « pedagogia pelo exemplo »).

É claro que esses princípios e as pistas concretas que os incorporam devem ser adaptados e não têm valor nem como modelos nem como receitas. Eles são apenas o resultado provisório de um estado de prática e de reflexão em um dado momento, mas sua apresentação pede uma internalização da questão pedagógica a partir da construção dos ensinamentos, qualquer que seja sua forma e o nível do público. A reflexão pedagógica faz parte da carreira acadêmica. A realização de um curso não se baseia apenas no domínio de um campo disciplinar, mas implica em selecionar e organizar o conhecimento a ser transmitido em um período de tempo limitado e para um determinado público. Para internalizar essa dimensão pedagógica no centro dos ensinamentos, a sociologia é um recurso. Sendo uma matéria a ser ensinada, ela requer uma circulação entre teorias e investigações e permite convencer as pessoas mais facilmente do interesse em perguntas ou em conceitos abstratos. Como disciplina de pesquisa, oferece ferramentas de reflexividade para pensar sobre os efeitos e a recepção das práticas de ensino e ajuda a se adaptar ao público. A sociologia, portanto, oferece, diante da pedagogia transversal promovida pelas autoridades oficiais das universidades e imposta de cima, ferramentas para recuperar essa questão e para defender um outro tipo de conhecimento pedagógico, nas mãos de professores-pesquisadores, ancorada em suas práticas reais e em sua especificidade disciplinar.

Indispensável para melhorar a transmissão, favorecendo um melhor ajuste para os alunos, essa reflexividade pedagógica não é menos limitada em seus efeitos devido às restrições materiais, temporais e organizacionais que pesam sobre os professores- 
pesquisadores e seu trabalho pedagógico. Se os experimentos e as reflexões existem, de forma isolada ou em coletivos informais, e trazem à vida uma pedagogia « de baixo », a fraca visibilidade dessas práticas não resulta apenas da falta de legitimidade. Acima de tudo, reflete a «missão impossível » enfrentada por professores- pesquisadores que não têm controle sobre suas condições de trabalho e que as vêem se deteriorar progressivamente com cortes no orçamento com conseqüências pedagógicas desastrosas.

\section{Referências}

ANGELOFF Tania, Céline BESSIERE, Avec la participation de : BONDUELLE Arnaud, Jéromine DABERT \& Gaston LAVAL, 2014, «Enseigner le genre : un devoir de dissidence. Retour sur quatre années d'introduction à la sociologie du genre à l'université ParisDauphine », Travail genre et sociétés, $n^{\circ} 31$, p. 85-99.

ARESER, 1997, Quelques diagnostics et remèdes urgents pour une université en péril, Paris, Liber-Raisons d'Agir.

AVRIL Christelle, Marie CARTIER \& Delphine SERRE, 2010, Enquêter sur le travail. Concepts, méthodes, récits, Paris, La Découverte.

BEAUD Stéphane, 1997, « Un temps élastique. Étudiants des « cités » et examens universitaires », Terrain, n²9, p. 43-58.

BIZEUL Daniel, 2007, «Que faire des expériences d'enquête ? Apports et fragilité de l'observation directe », Revue française de science politique, vol. 57, n¹, p. 69-89.

BODIN Romuald \& MILLET Mathias (2011), «L'université, un espace de régulation. L'"abandon" dans les premiers cycles à l'aune de la socialisation universitaire », Sociologie, vol. 2, $\mathrm{n}^{\circ} 3$, p. 225-242.

BOLTANSKI Luc \& Ève CHIAPELLO, 1999, Le nouvel esprit du capitalisme, Paris, Gallimard.

BOURDIEU Pierre, Jean-Claude PASSERON \& Monique DE SAINT-MARTIN, 1965, Rapport pédagogique et communication, Cahiers du CSE, Mouton.

BOURDIEU Pierre \& Jean-Claude PASSERON, 1964, Les Héritiers. Les étudiants et la culture, Paris, Minuit. 
BOURDIEU Pierre \& Jean-Claude PASSERON, 1970, La Reproduction. Eléments pour une théorie du système d'enseignement, Paris, Minuit.

BOURGIN Joëlle, 2011, « Les pratiques d'enseignement dans l'université de masse : les premiers cycles universitaires se scolarisent-ils ? ", Sociologie du travail, vol. 53, n40, p. 93-108.

BOYER Régine \& Charles CORIDIAN, 2002, « Transmission des savoirs disciplinaires dans l'enseignement universitaire. Une comparaison histoire / sociologie », Sociétés contemporaines, $n^{\circ} 48$, p. 41-61.

BOYER Régine \& Charles CORIDIAN, 2001, «Enseigner en première année de l'université de masse », Recherche et formation, $n^{\circ} 38$, p. 141-153.

CHAPOULIE Jean-Michel, 2000, « Enseigner le travail de terrain et l'observation : témoignage sur une expérience (1970-1985) », Genèses, n³9, p. 138-155.

CHAPOULIE Jean-Michel, 1979, « La compétence pédagogique des professeurs comme enjeu de conflits ", Actes de la recherche en sciences sociales, nº, p. 65-85.

DAMAMME Dominique (2008), «Laboratoires de la réforme pédagogique », in Dominique DAMAMME, Boris GOBILLE, Frédérique MATONTI et Bernard PUDAL(dir.), Mai Juin 68, Paris, Editions de l'Atelier, p. 245-258

DARMON Muriel, 2013, Classes préparatoires. La fabrique d'une jeunesse dominante, Paris, La Découverte.

DEAUVIEAU Jérôme, 2007, « Observer et comprendre les pratiques enseignantes », Sociologie du travail, vol. $49, \mathrm{n}^{\circ} 1, \mathrm{p} .100-118$.

DUGUET Amélie, 2015, « Les pratiques pédagogiques à l'université en France : quels effets sur la réussite en première année ? Le cas du cours magistral », Recherche et formation, n'79, p. 9-26.

DUGUET Amélie, 2018, « Le cours magistral en première année universitaire : des pratiques pédagogiques rénovées ? ", Carrefours de l'éducation, n45, p. 93-113.

DURKHEIM Emile, 1992, Éducation et sociologie, Paris, Quadrige/PUF, première édition 1922.

FAURE Sylvia, Mathias MILLET \& Charles SOULIE, 2005, Enquête exploratoire sur le travail des enseignants-chercheurs. Vers un bouleversement des valeurs académiques ?, Rapport d'enquête.

GADEA Charles et SOULIE Charles (2000), « Réflexions sur une expérience d'initiation à la recherche en sociologie à l'Université (1994-2000) », Genèses, n³9, p. 155-171. 
GARCIA Sandrine, 2008a, «L'expert et le profane : qui est juge de la qualité universitaire ? ", Genèses, n¹70, p. 66-87.

GARCIA Sandrine, 2008b, "L'évaluation des enseignements : une révolution invisible », Revue d'histoire moderne et contemporaine, $n^{\circ} 55-4$ bis, p. 46-60.

GAXIE Daniel, 1990, «Au-delà des apparences... Sur quelques problèmes de mesure des opinions ", Actes de la recherche en sciences sociales, $n^{\circ} 81-82$, p. 97-112.

GOERTZ Gary \& Amy G. MAZUR, 2008, « Mapping gender and politics concepts: ten guidelines », dans GoERTZ Gary \& Amy G. MAZUR (Ed.), Politics, Gender, and Concepts. Theory and Methodology, New York, Cambridge University Press, p. 14-43. GOODY Jack, 1979, La Raison graphique, Paris, Minuit.

HEYDE Martine \& Laurence LE DIOURIS, 2009, « Trois années d'évaluation des enseignements par les étudiants dans une université de masse. Pourquoi ? Comment ? Et après ? ", dans ROMAINVILLE Marc \& Cristina COGGI (dir.), L'évaluation de l'enseignement par les étudiants. Approches critiques et pratiques innovantes, Bruxelles, De Boeck Supérieur, p. 57-72.

HOCQUELET Mathieu \& Lydie LAUNAY, 2009, « Le monitorat comme point de vue sur les transformations de l'université : du dysfonctionnement global à l'inadéquation aux SHS », dans TIFFON Guillaume \& Virginie GARCIA (dir.), Le sociologue en train de se faire. Travail réflexif sur le statut d'étudiant-enseignant-chercheur, Paris, L'Harmattan, p. 23-46.

JOUNIN Nicolas, 2014, Voyage de classes. Des étudiants de Seine-Saint-Denis enquêtent dans les beaux quartiers, Paris, La Découverte.

LAHIRE Bernard, 2000, «Conditions d'études, manières d'étudier et pratiques culturelles », dans GRIGNON Claude (dir.), Les Conditions de vie des étudiants, Paris, PUF, p. 241-381.

LAHIRE Bernard, 2002, «Formes de la lecture étudiante et catégories scolaires de l'entendement lectoral », Sociétés contemporaines, n48, p. 87-107.

LOIOLA Francisco \& Marc ROMAINVILLE, 2008, « La recherche sur la pédagogie de l'enseignement supérieur. Où en sommes-nous ? ", Revue des sciences de l'éducation, vol. 34, n'3, p. 529-535.

MASSON Philippe, 2005, "Premières réceptions et diffusions des Héritiers (1964-1973) », Revue d'histoire des sciences humaines, $\mathrm{n}^{\circ} 13$, p. 69-98.

MERLE Pierre, 2007, Les Notes. Secrets de fabrication, Paris, PUF.

MUSSELIN Christine, 2005, Le Marché des universitaires : France, Allemagne, États-Unis, Paris, Presses de Sciences-Po. 
OLIVIER DE SARDAN Jean-Pierre, 2000, « Le "je" méthodologique. Implication et explicitation dans l'enquête de terrain ", Revue française de sociologie, vol. 41, n³, p. 417445 .

PINTO Vanessa, 2010, «L'emploi étudiant et les inégalités sociales dans l'enseignement supérieur », Actes de la recherche en sciences sociales, n¹83, p. 58-71.

SIRACUSA Jacques, 2008, Vacances sociologiques. Enseigner la sociologie à l'université, Saint-Denis, Presses Universitaires de Vincennes.

SOULIE Charles, 2002, "L'adaptation aux "nouveaux publics" de l'enseignement supérieur : auto-analyse d'une pratique d'enseignement magistral en sociologie », Sociétés contemporaines, $n^{\circ} 48$, p. 11-39.

SOULIE Charles, 2017, «La pédagogie charismatique de Gilles Deleuze à Vincennes », Actes de la recherche en sciences sociales, $n^{\circ} 216-217$, p. 42-63.

SOUTRENON Emmanuel, 2005, "Le "questionnaire ethnographique". Réflexions sur une pratique de terrain ", Genèses, n60, p. 121-137.

Recebido em: 10/02/2020 Aprovado em: 22/03/2020

Universidade do Estado de Santa Catarina - UDESC Programa de Pós-Graduação em Educação - PPGE

Revista Linhas

Volume 21 - Número 45 - Ano 2020 revistalinhas@gmail.com 